Binghamton University

The Open Repository @ Binghamton (The ORB)

The Society for Ancient Greek Philosophy Newsletter

4-26-1996

\title{
Aristotle and Chrysippus on the Physiology of Human Action
}

Priscilla Sakezles

University of Akron, pks@uakron.edu

Follow this and additional works at: https://orb.binghamton.edu/sagp

Part of the Ancient History, Greek and Roman through Late Antiquity Commons, Ancient Philosophy Commons, and the History of Philosophy Commons

\section{Recommended Citation}

Sakezles, Priscilla, "Aristotle and Chrysippus on the Physiology of Human Action" (1996). The Society for Ancient Greek Philosophy Newsletter. 454.

https://orb.binghamton.edu/sagp/454

This Article is brought to you for free and open access by The Open Repository @ Binghamton (The ORB). It has been accepted for inclusion in The Society for Ancient Greek Philosophy Newsletter by an authorized administrator of The Open Repository @ Binghamton (The ORB). For more information, please contact ORB@binghamton.edu. 
Aristotle and Chrysippus on the Physiology of Human Action by Priscilla Sakezles University of Akron

Presented to SAGP at the Central American Philosophical Association meeting Chicago, April 26,1996

The early stoics do not seem to have physiological theories about the workings of the human body. This is not surprising in light of Chrysippus' admission, reported by Galen, of his ignorance of anatomy. ${ }^{1}$ Yet a physiological theory explaining the mechanics of how the body moves in response to the soul's desires can be reconstructed from a handful of neglected fragments. Interestingly, the revealed theory is nearly identical to Aristotle's explanation in on the Motion of Animals of "how the soul moves the body in voluntary motion" (700b10 and 703b3). In this paper I reconstruct the stoic theory, and argue that it is most likely adopted directly from Aristotle.

I make this claim pace F.H. Sandbach, who in 1985 published a monograph, Aristotle and the stoics, in which he argues for two theses, a stronger and a weaker: the former is that "Aristotle was not a significant influence on early, that is on third-century, stoicism" (56), and the latter is that "it is a mistake to proceed on the a priori assumptions that the stoics must have known the opinions expressed in his school-works, must have understood his importance sub specie aeternitatis, and must therefore have been influenced by him" (57). Sandbach's strategy for proving these two claims is essentially negative: there is no certain and positive evidence to show that the stoics did know Aristotle's works or views, therefore we must not think that they did so. Apparent similarities, he thinks, must be coincidental, and he prefers to think of the stoics as original rather than as responding, positively or negatively, to Aristotelian theories. He occasionally suggests Academic influence, but as David Hahm points out in his excellent critique of this work, Sandbach's negative methodology makes it difficult to advance any hypothesis of influence on the stoics.2 I agree with Hahm's final estimation of Sandbach's work: given the lack of direct evidence for influence, scholars are unwarranted in assuming that such influence existed--thus Sandbach's weaker claim is true, and he has done a great service to ancient scholarship by challenging us to be more careful whenever we attribute an Aristotelian view to the stoics. But the stronger claim is not proven true, because lack of direct evidence does not prove the absence of influence. Rather, it indicates that our claims of influence must rest on the strength of our indirect evidence, viz. similarity of theory. In this paper I will present what seems to me compelling evidence that the stoics not only knew of, but even adopted Aristotle's physiological description of human action. My methodology will be to show that there is a very high degree of similarity between the Aristotelian and stoic theories; that as far as we can tell from the extant remains no one else besides Aristotle had such a theory which could have influenced the stoics; and that given the peculiarity of the theory, it is highly unlikely that the stoics formulated this theory independently of its inventor who lived in such close temporal and spatial proximity. ${ }^{3}$ But before

${ }^{1}$ On the Doctrines of Hippocrates and Plato 1.6 .13$.

"Aristotle and the Stoics: A Methodological Crux," 300-301.

${ }^{3}$ Consider the story of the fate of Aristotle's written work. When he died in 322 B.C.E. he left his library to his successor Theophrastus. When Theophrastus died in 288 he left his and Aristotle's library to Neleus of skepsis. When Neleus died he left them to his non-philosophical relatives, 
I address the specific thesis regarding the physiological description of action, I will briefly sketch the larger similarity between Aristotle and the stoics which makes this thesis significant.

I

I believe that Stoic determinism, especially as applied to human action, is heavily indebted to Aristotle. One of the most striking similarities between Aristotle and the Stoics is how they explain human action. Both explain action in terms of a psychological and a physiological aspect. Regarding the former, the psychological aspect, their theories are quite. similar though they use different terminology. Aristotle says we perceive an object of desire or avoidance, we deliberate and choose, or engage in a practical syllogism, then we move towards or away from the object. The stoics say we receive an impression of an object of our impulse (iop $\dot{\eta}$, they rarely use the term "desire", op $\epsilon \xi(\zeta)$, then we assent to the proposition that we ought to have that object and we experience an impulse or movement towards the object. While Aristotle and the stoics describe what happens at the psychological level similarly, I think the corresponding events occurring at the physiological level are nearly identical. I will argue for that thesis in detail shortly. At this point I will just assume my final conclusion that the Stoics adopted Aristotle's physiological account of human action.

Starting from this thesis we can find in Aristotle's philosophy other views, some more implicit than explicit, which when combined yield a. completely deterministic stoic theory, even including the peculiar doctrine of eternal recurrence. For instance, despite Aristotle's avowed libertarianism, particularly in the Nicomachean Ethics, there are deterministic strains in his philosophy. In Metaphysics 9.5 Aristotle is discussing the potentialities of rational versus non-rational beings, and he says of the latter--the nonrational:

When the agent and the patient meet in the way appropriate to the potentiality in question, the one must act and the other be acted on, but with the former kind [rational beings] this is not necessary. For the non-rational potentialities are all productive of one effect each, but the rational produce contrary effects. . . . That which decides ( $\tau$ ò кúlov) must be . . . desire or choice. For whichever of two things the animal desires decisively ( $\kappa v p i \omega s)$, it will do, when it is in the circumstances appropriate to the potentiality in question and meets the passive object. Therefore everything which has" a rational potentiality,

who hid them in a cellar to avoid confiscation by the book-buyers for the great libraries at Alexandria and Pergamum. But eventually they were sold to Apellicon of Teos in the first century B.C.E., then exported to Rome where Andronicus of Rhodes finally catalogued and published them around 30-20 B.C.E. Sandbach leans heavily on this story to argue that Aristotle's written work was unavailable, and hence unknown, for most of the Hellenistic period. However, by the time Theophrastus died and the books supposedly disappeared, zeno of Citium--the founder of the Stoa--had been living in Athens for some 24 years and running the stoa for 13. It is also quite likely that there were other copies of Aristotle's works in circulation, or copies of notes by his students, and that his views were known by word of mouth. Also, the Lyceum remained active at least through the time of Strato (c.270 B.C.E.), which was about ten years after Chrysippus' birth. So zeno could have had access to Aristotle's own library before Theophrastus died, and he and cleanthes surely had contact with the stili-active Lyceum before and after Theophrastus' death. Athens was a small town, and the philosophers were sociable, if sometimes hostile. All things considered, it is highly unlikely that the early stoics were completely ignorant of Aristotle's philosophy. 
passive object. Therefore everything which has a rational potentiality, when it desires that for which it has a potentiality and in the

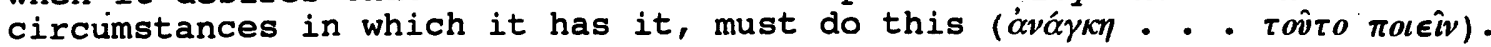
(1048a6-15)

Now I suspect Aristotle would deny this, but what this text suggests is that whenever the sufficient conditions for performing an action exist, that action follows of necessity. If the stoics coupled Aristotle's physiological account of action with this view that sufficient conditions necessitate their effects, the result would be a physical determinism. And if this determinism--the view that everything happens of necessity--were coupled with Aristotle's thesis in On Generation and Corruption 2.11 that whatever is necessary is eternal and cyclical, the result would be the stoic doctrine of eternal recurrence. I.e., everything that happens occurs as it does necessarily; whatever occurs. necessarily must continue to occur in an eternal cycle; therefore everything that happens continues to happen over again in an eternal cycle. I will not argue for these larger claims in this paper, but present them to set the context for my thesis that the stoics adopted Aristotle's physiological explanation of human action. 4

In part II I will describe Aristotle's physiological theory. In part III I will reconstruct the stoic theory, and then the similarity of the two will be apparent. But before I can safely conclude that the stoics adopted Aristotle's theory I must show that similar theories were not available to the stoics from any other source. To this end, part IV will survey relevant medical and physiological research from its beginnings in the generation before Aristotle to the time of Chrysippus.

II

In On the Motion of Animals Aristotle addresses the cause of animal and human motion. After discussing the practical syllogism--the psychological aspect of action--he says that animals are analogous to "automatic puppets." specifically our bones and sinews are like their pegs and strings. This introduces the mechanical physiological side of the story. The difference between us and the puppets is that we have organic parts capable of alteration.

What happens is this: The first necessary condition for movement is experiencing some form of desire for an object. Children and non-human

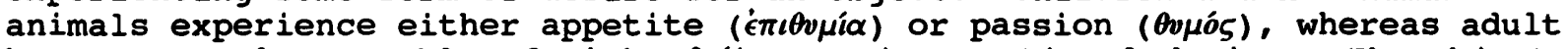

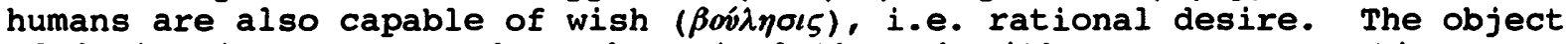
of desire is represented to the animal through either sense-perception or imagination ( $\left.\phi \alpha \nu \tau \alpha \sigma^{\prime} \alpha\right)$ or, in the case of humans, thought. The perception,

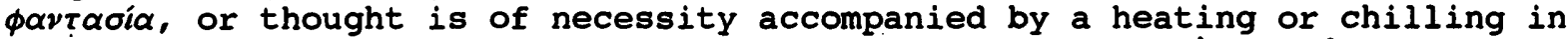

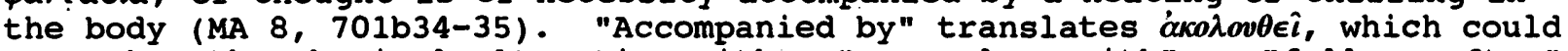
mean that the physical alteration either "goes along with" or "follows after" the psychological phenomenon that corresponds to it. Aristotle seems a bit ambivalent regarding the strength of the connection between the

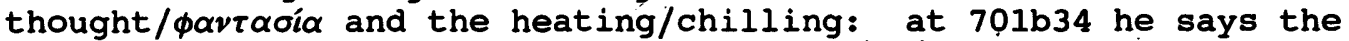

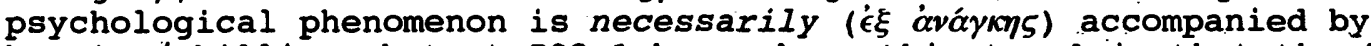
heating/chilling, but at 702 al he weakens this to claim that the former is nearly always ( $\pi \alpha \dot{\nu} \tau \alpha \sigma \chi \epsilon \delta \grave{\nu}$ ) accompanied by the latter. The precise relationship between the psychological and the physical phenomena raises the

${ }^{4}$ I am not making the very strong (and I believe untenable) claim that stoic determinism is entirely the product of Aristotelian theories. There are undoubtedly many different influences that would go into a complete explanation of the origin of this peculiar theory; I am merely focusing on what I consider to be one very important influence. Other scholars will work on the other influences, and we may eventually have a complete and coherent understanding of the genesis of stoic determinism. 
while this issue is relevant to my topic, there is insufficient space to address it here. For present purposes, it seems safe to conclude that in Aristotle's mind the perception, image, or thought of a painful or pleasant object occurs always or almost always along with a physical chilling or heating. Aristotle claims that feelings of desire or avoidance are necessarily accompanied by heating or chilling of a body part or sometimes the whole body based on his observation that, e.g., sexual desire makes one feel flushed and fear makes one feel cold.

Aristotle locates this heating or chilling specifically in the $\pi v \in \hat{v} \mu \alpha$ (pneuma) in the heart. $\pi v \in \hat{v} \mu \alpha$ is a hot and airy material stuff, usually translated "breath" or "air," about which I will have much to say. Recall, of course, that Aristotle thinks the heart is the center of perceptual activity, and the brain's function is merely to cool the body. ${ }^{5}$ The heart, in addition to being full of blood, contains $\pi v \in \hat{v} \mu \alpha$. When this $\pi v \in \hat{v} \mu \alpha$ is heated or chilled it expands or contracts, ${ }^{6}$ and this, Aristotle says, pushes or pulls the connected body parts (sinews and bones), and thus movement is relayed throughout the joints of the body until we get up and walk towards or flee from the object of our desire or avoidance. In this description, movement originates in the $\pi v \in \hat{v} \mu \alpha$ in the heart and extends outward to the limbs. What makes this account so significant is that it is the first theory to give us a stage-by-stage description of how psychological phenomena are translated into bodily action.

This account of movement only explicitly mentions $\pi v \in \hat{v} \mu \alpha$ in the heart, but Aristotle's biological works suggest that $\pi v \epsilon \hat{v} \mu \alpha$ plays a larger role, especially in reproduction and sense perception. ${ }^{7}$ In the Generation of Animals $2.3^{\prime}$ we learn that the male's semen contains $\pi v \in \hat{v} \mu \alpha$, which is the

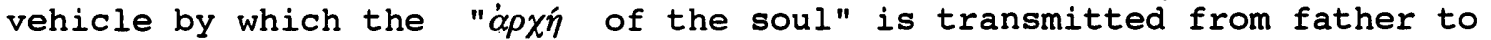
offspring. Here $\pi v \in \hat{v} \mu \alpha$ is said to be analogous to the element of the stars, i.e., the fifth element ether. In discussing spontaneous generation in 3.11 Aristotle argues that since earth contains water, and water contains $\pi \nu \in \hat{v} \mu \alpha$, and all $\pi v \epsilon \hat{v} \mu \alpha$ contains "soul-heat", then "in a way all things are full of soul" (762a19-22). The first passage elevates the status of $\pi v \in \hat{v} \mu \alpha$ to something nearly divine, while the second passage makes $\pi v \in \hat{v} \mu \alpha$ nearly ubiquitous (in the sublunary region); this anticipates the role of $\pi v \in \bar{v} \mu \alpha$ in stoic philosophy as a truly divine and ubiquitous substance. Aristotle later comments on the wide usage of $\pi v \in \hat{v} \mu \alpha$ : "So it is reasonable that nature should perform most of her operations using breath [ $\pi v \epsilon \hat{v} \mu \alpha]$ as an instrument, for as

${ }^{5} \mathrm{E} \cdot \mathrm{g} .$, Parts of Animals 3.4, 666al1-13; On Sleep 2, 455b34-456a6; On Youth and old Age 3.

${ }^{6}$ This expansion and contraction is mentioned in at least three places:

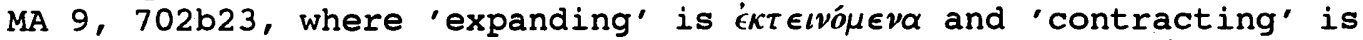

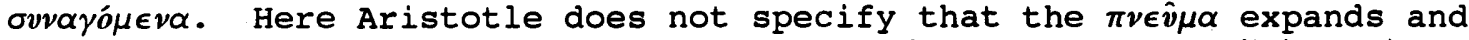
contracts, but says only that "the parts adjacent to the origin" (i.e. the body's center: the heart) are altered thusly.

2) MA 10, 703a20-21, where 'expanding' is $\alpha \dot{v} \xi \dot{\alpha} v \epsilon \sigma \theta \alpha \iota$ and 'contracting' is $\sigma v \sigma \tau \epsilon \bar{\lambda} \lambda \epsilon \sigma \theta \alpha$. Here Aristotle says quite explicitly that the $\pi v \in \hat{v} \mu \alpha$ itself expands and contracts.

3) $\mathrm{PA} 3.4,666 \mathrm{~b} 14-18$ : "The heart again is abundantly supplied with sinews $(v \in \hat{v} \rho \omega v)$, as might reasonably be expected. For the motions of the body commence from the heart, and are brought about by traction ("̈ $\lambda \kappa \in \iota \nu)$ and relaxation ('́丿ví́val). The heart therefore, which, as already said, is as it were a living creature inside its possessor, requires some such subservient and strengthening parts."

${ }^{7}$ Aristotle mentions $\pi v \in \hat{v} \mu \alpha$ here and there throughout on the Generation of Animals; see Peck's "The Connate Pneuma" for an analysis of the role of $\pi v \in \hat{v} \mu \alpha$ in reproduction and sensation. 
some instruments serve many uses in the arts, e.g. the hammer and anvil in the smith's art, so does breath in things formed by nature" (5.8, 789b7-11). In Generation of Animals 2.6 he says that "smell and hearing are passages full of innate $\pi v \in \hat{v} \mu \alpha$, connecting with the outer air and terminating at the small blood-vessels around the brain which extend thither from the heart" (744a1-5). In Parts of Animals 2.10 he says the eyes, and again the ears, have passages running from them to the blood-vessels around the brain. Here he does not mention $\pi v \in \hat{v} \mu \alpha$, but says the ear is full of air. Elsewhere Aristotle says $\pi v \in \hat{v} \mu \alpha$ is air, or a type of air, ${ }^{8}$ so perhaps it is implicit that the passages from the eyes and ears contain $\pi v \in \hat{v} \mu \alpha$. (These "passages" were later discovered to be nerves by Herophilus and Erasistratus, who continued to believe them to be filled with $\pi v \in \hat{v} \mu \alpha$.$) .) And although it is not explicit in$ the texts, it seems that all the blood is charged with $\pi v \in \hat{v} \mu \alpha$ when it is first manufactured in the heart. 9 In fact, only $\pi v \in \hat{v} \mu \alpha$ in the blood-vessels could account for a flow of perceptual information into the heart, because Aristotle is explicit in PA 3.4 that blood originates in the heart and flows outward through the veins, and no blood enters into the heart from outside it (666a68), and he also insists that blood is merely a nutriment in the body and as such cannot itself enable us to perceive. ${ }^{10}$ If we can assume that the veins contain $\pi v \epsilon \hat{v} \mu \alpha$, sense-perception is explained as follows.

Let us take the simpler case of seeing or hearing. Aristotle rejects the effluence theories of the atomists and Empedocles, which claim that objects give off particles which come into direct contact with the sense organ. Rather, there must be an intermediate substance such as air or water which transmits "movements" from the object to the sense organ (De Sensu 2, 438b3-5). When Aristotle defines perception as taking in the object's form without its matter, these "movements" may be the physiological counterpart of this "form."11 so these movements travel from the object to the sense organ via some intermediate substance, then they travel through the $\pi v \in \hat{v} \mu \alpha$ in the sense organ's "channels," then through the $\pi v \epsilon \hat{v} \mu \alpha$ in the blood through the blood-vessels, first going around the brain then to the heart where they register as perceptions in or by the "common sense". 12

Thus the $\pi v \epsilon \hat{v} \mu \alpha$ would function in two directions: sense perception is explained by movements traveling from the sense organs inward to the heart; and bodily motion, which is the animal's response to the perceptions it receives, is explained by the expansion and contraction of $\pi v \in \hat{v} \mu \alpha$ in the heart being relayed outward to the limbs.

${ }^{8} \mathrm{GA} 2.2,736 \mathrm{a} 1$.

${ }^{9}$ Arthur Peck argues thus in "The Connate Pneuma" 115 and 119 , and in the Loeb edition of GA, Ixiv and appendix B. Von Staden endorses Peck's view in Herophilus, 266.

${ }^{10}$ This is one reason why I think Peck is right. Note PA 3.4, 666a13-14: "The motions of pain and pleasure, and generally of all sensation, plainly have their source ( $\left.\dot{\alpha} \rho \chi \alpha^{\prime} \mu \epsilon v \alpha l\right)$ in the heart, and find in it their termination ( $\pi \epsilon \rho$ aivovoal)." Could this allude to the heart's two-way function of receiving sensations (qua motions) from outside and sending out another motion in response?

${ }^{11}$ In Aristotle: The Desire to Understand, Jonathan Lear suggests that when Aristotle says the sense organ receives the form of the perceived thing without its matter (DA 425b23), he means not that the organ is literaliy made like the object in quality (e.g. redness), but rather receives a coded message, e.g. a vibration, which somehow represents its object (116).

${ }^{12}$ The "common sense" itself seems to be composed of $\pi v \in \hat{v} \mu \alpha$. On this see Ross' introduction to De Sensu and De Memoria, 14-20. 
III

Now for the stoics.13 The stoics are materialists, so that soul and body are both corporeal. The world is composed of matter which is passive, and god which is active and shapes the matter. ${ }^{14}$ More specifically, the world is composed of earth, water, air, and fire; earth and water are passive, while air and fire are active. Fire and air together compose $\pi v \in \hat{v} \mu \alpha$, and the hot fire's expansion seems to conflict with the cold air's contraction in such a way as to produce a kind of motion. The details here are quite obscure, but $\pi v \in \hat{v} \mu \alpha$ can be qualitatively altered to take various forms, where the "tension" ( $\tau$ ówos) of a body's $\pi v \in \hat{v} \mu \alpha$ determines what sort of body it is. The active $\pi v \in \hat{v} \mu \alpha$ "sustains" or "holds together" (ovvé $\chi \epsilon \iota v$ ) the passive matter, giving form and quality to bodies. Inanimate bodies such as sticks and stones contain $\pi v \epsilon \hat{v} \mu \alpha$ in the simplist form, called "tenor" ( $\check{\epsilon} \xi \iota \zeta)$. Plants contain $\pi v \in \hat{v} \mu \alpha$ in the form of "physique" ( the form of soul $\left(\psi v \chi^{\prime}\right)$, and humans also contain it in the form of rational soul. The more complex bodies include the less complex forms of $\pi v \in \hat{v} \mu \alpha$ as well: e.g., our bones are like stones, and our nails and hair are like plants. ${ }^{15}$ The unity of these different types of matter within a single animal or human body is explained by the stoics in terms of mixture: "An animal is a composite of body and soul. . . [which are] blended through and through."16 Our soul, then, is $\pi v \in \hat{v} \mu \alpha$ (itself material: fire and air) in a certain form, which is mixed throughout the body.

The stoics describe the soul- $\pi v \in \hat{v} \mu \alpha$ not only as mixed with the body, but also as extending throughout the body with parts like the tentacles of an

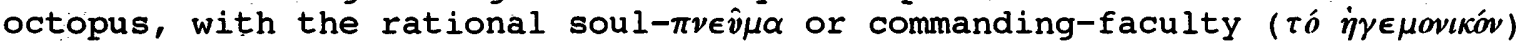
localized in the heart. ${ }^{17}$ Aetius reports:

The stoics say that the commanding-faculty is the soul's highest part, which produces impressions, assents, perceptions and impulses.... From the commanding-faculty there are seven parts of the soul which grow out and stretch out into the body like the tentacles of an octopus. Five of these are the senses, sight, smell, hearing, taste and touch. sight is $\pi v \in \hat{v} \mu \alpha$ which extends from the commanding-faculty to the eyes, hearing is $\pi v \epsilon \hat{v} \mu \alpha$ which extends from the commanding-faculty to the ears. . . Of the remainder, one is called seed, and this is $\pi v \in \hat{v} \mu \alpha$ extending from the commanding-faculty to the genitals. The other, . . which they also call utterance, is $\pi v \in \hat{v} \mu \alpha$ extending from the commanding-faculty to the

${ }^{13}$ In what follows I am speaking of the views of Chrysippus. Often our sources treat Chrysippus' theories as representative of the whole school; where we know that Chrysippus' theories differ from Zeno's and/or Cleanthes', I will refer only to the former. See Hahm's The Origins of stoic Cosmology for a detailed analysis of the development of stoic cosmology from zeno to Chrysippus; chapter 5, "Cosmobiology," is especially pertinant to my topic, although Hahm does not recognize the physiological theory I attribute to Chrysippus.

${ }^{14}$ Diogenes Laertius vii.134.

${ }^{15} \mathrm{Phil0}$, Allegories of the Laws 2.22-3 (SVF 2.458, part; Long and Sedley 47P). (In all following notes I will refer to Long and Sedley's The Hellenistic Philosophers as LS.)

${ }^{16} \mathrm{Hierocles,} \mathrm{Elements} \mathrm{of} \mathrm{Ethics} 4.38$ (LS $\left.53 \mathrm{~B}(5)\right)$.

${ }^{17}$ Galen, On the Formation of the Foetus 4.698, 2-9 (SVF 2.761, part; LS 53D); On the Doctrines of Hippocrates and Plato 5.2.49, 5.3 .1 (SVF 2.841, part; LS 53U). 
pharynx, tongue and appropriate organs. ${ }^{18}$

Chrysippus used the spider analogy to make the same point:

In the same way as a spider in the center of the web holds in its feet all the beginnings of the threads, in order to feel by close contact if an insect strikes the web, and where, so does the ruling part of the soul, situated in the middle of the heart, check on the beginnings of the senses, in order to perceive their messages from close proximity. ${ }^{19}$

As materialists it is easier for the stoics to explain soul-body interaction, and another fragment reports that:

by stretching out ( $\tau \epsilon \iota \nu \rho \mu \dot{\epsilon} \nu \eta \ddot{\epsilon} \xi \omega^{20}$ ) and relaxing $\left(\mu \epsilon \tau^{\circ} \dot{\alpha} \phi \epsilon \in \sigma \epsilon \omega \varsigma\right)$, the soul makes an impression on all the body's parts, since it is blended with them all, and in making an impression it receives an impression in response. For the body, just like the soul, reacts to pressure; and the outcome is a state of their joint pressure upon, and resistance to, each other. From the outermost parts inclining within, it travels .. . to the commanding faculty, with the result that there is an awareness both of all the body's parts and of the soul's. This is equivalent to the animal's perceiving itself. ${ }^{21}$

This "stretching out" and "relaxing" and "joint pressure" here explains the commanding faculty's awareness of and communication with its own body. For the Stoics, receiving an impression from a desired object is the first necessary condition for action. Chrysippus defines impression as "a printing in the soul, i.e., an alteration," and it occurs specifically in the soul- $\pi v \epsilon \hat{v} \mu \alpha$ of the commanding-faculty in the heart. ${ }^{22}$ Our sense organs are constantly stimulated by external objects, and since the soul and body are blended, an affection travels from, say, our eyes, through our soul- $\pi v \in \hat{v} \mu \alpha$ to our commanding-faculty in the heart, where it enters our conscious awareness. This is very similar to Aristotle's description of perception, except that the soul- $\pi v \in \hat{v} \mu \alpha$ is said to be blended with the body instead of being confined to passages and blood-vessels.

The second necessary condition for and efficient cause of action is experiencing an "impulse" ( $(\rho \mu \mu \dot{\eta})$ towards the desired object or a "repulsion" $(\dot{\alpha} \phi \rho \rho \dot{\eta})$ away from an unwanted object. Impulse and repulsion, like Aristotle's desire and aversion, are both psychological and physiological phenomena. Under its psychological description, impulse in humans is defined as "a movement of thought towards something in the sphere of action," ${ }^{23}$ and the Stoics insist that all human impulse is rational because the soul has no irrational parts. So how do the stoics account for vice? They say that some impulses are "excessive" and "disobedient to reason," and such impulses are

${ }^{18}$ Aetius 4.21.1-4 (SVF 2.836, part; LS 53H).

${ }^{19}$ Chalcidius, Commentary on the Timaeus, 220 (SVF 2.879); Sambursky's translation, Physics of the stoics, 24.

${ }^{20}$ This is the same terminology used by Aristotle for expansion--

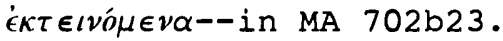

\footnotetext{
${ }^{21}$ Hierocles, Elements of Ethics $4.38-53$ (LS 53B(6)-(9)).

${ }^{22}$ Diogenes Laertius 7.50 (SVF 2.55; LS 39A(3)).

${ }^{23}$ Stobaeus 2.86, 17-87, 6 (SVF 3.169, part; LS 53Q).
} 
called "passions" $(\pi \alpha \dot{\theta} \theta) \cdot{ }^{24}$ Note that a passion is not an "emotion" in our sense, but rather refers specifically to an excessive impulse; the stoics countenance many emotions as appropriate impulses, as long as they are not excessive. They divide all moderate impulses into joy, watchfulness, and wishing. Joy includes delight, sociability, cheerfulness; watchfulness includes respect, cleanliness; and wishing includes kindness, generosity, warmth, affection. ${ }^{25}$ There are four species of passion: appetite, pleasure, fear, and distress; and all vices are subsumed under one of these (e.g., appetite includes anger, intense sexual desire, cravings and yearnings, love of pleasure and riches and honours). ${ }^{26}$ since all human impulses are rational, passions are also:

Passion is no different from reason, and there is no dissension and conflict between the two, but a turning of the single reason in both directions, which we do not notice owing to the sharpness and speed of the change. . . . Appetite and anger and fear and all such things are corrupt opinions and judgements, which do not-arise about just one part of the soul but are the whole commanding-faculty's inclinations, yieldings, assents and impulses. ${ }^{27}$

My description of impulse and passion has so far addressed only the psychological aspect. The physiological description of impulse must be reconstructed from fragments whose significance, I believe, has lain unrecognized. Galen, in on the Doctrines of Hippocrates and Plato, criticizes Chrysippus' denial of irrational parts of the soul. In the course of his criticism he reports Chrysippus definitions of distress and pleasure, two of the four species of passion or excessive impulse. Galen says that Chrysippus first defines distress as "a fresh belief that evil is present" and pleasure as "a fresh belief that good is present" (4.2.1). Galen complains that Chrysippus then contradicts himself in offering this second definition:

In defining distress, he [Chrysippus] says that it is "a shrinking at what is thought to be something to avoid," and he says pleasure is "a swelling up at what is thought to be something to pursue." 28

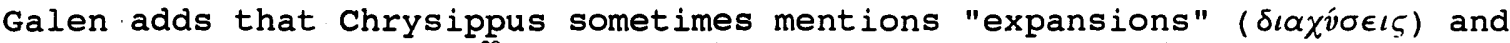

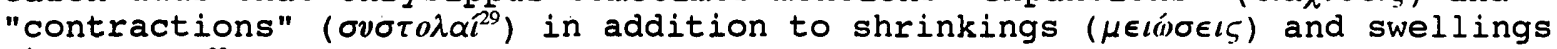
('́x $\alpha \rho \sigma \epsilon \iota \zeta) .{ }^{30}$ Galen's complaint is that the first definition is in terms of the rational part of the soul and the second is in terms of an irrational part, but Chrysippus denies the existence of an irrational part. I am here unconcerned with the details of Galen's criticism. What is relevant is that Galen has just revealed the psychological and physiological descriptions of

\footnotetext{
${ }^{24}$ Stobaeus $2.88,8$ (SVF 3.378, part; LS 65A(1)).

${ }^{25}$ Diogenes Laertius 7.116 (SVF 3.431; LS 65F).

${ }^{26}$ Stobaeus $2.90,19-91,9$ (SVF 3.394, part; LS 65E)

${ }^{27} \mathrm{Plutarch}$, On Moral Virtue 446F-447A (SVF 3.459, part; IS 65G).

${ }^{28}$ On the Doctrines of Hippocrates and Plato 4.2 .5 (SVF 3.463 , part; LS

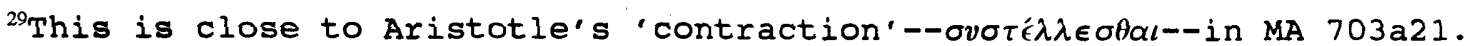

${ }^{30}$ On the Doctrines of Hippocrates and Plato 4.2 .6 (LS 65D(5)). These
} $65 D(4))$. terms recur at 4.3 .2 (LS $65 \mathrm{~K}(1)$ ). 
passion and impulse. He sees these two descriptions as contradictory, but I believe they are in fact complementary, in the same way Aristotle's

psychological and physiological accounts of desire are complementary: they are two descriptions of a single phenomenon. The second definition Galen reports reveals the physiological guise of impulse: it is an expansion or contraction; and since impulse and passion are activities of the commanding-faculty or rational soul, which is a certain form of $\pi v \in \hat{v} \mu \alpha$ centralized in the heart, it must be this $\pi v \in \hat{v} \mu \alpha$ in the heart which expands and contracts. Impulse is for the stoics the efficient cause of action, so it seems quite probable that they explained bodily movement in terms of this expansion and contraction of soul$\pi v \in \hat{v} \mu \alpha$.

Other sources show that all four species of passion were described in terms of expansion and contraction. Two centuries before Galen, Andronicus reported these definitions of the four passions:

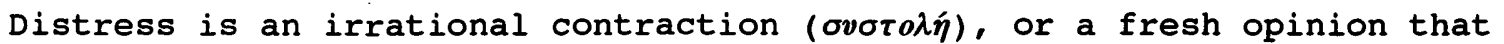
something bad is present, at which people think it right to be

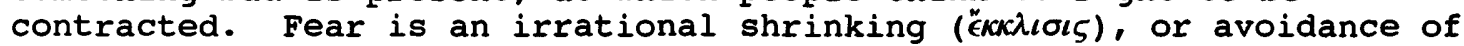
an expected danger. Appetite is an irrational stretching (desire, $\tilde{o} \rho \epsilon \xi(\zeta)$, or pursuit of an expected good. Pleasure is an irrational

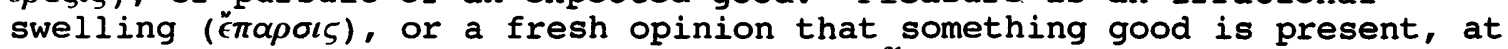
which people think it right to be swollen. ${ }^{31}$

Much later Stobaeus repeats that all the passions are either expansions or contractions:

In the case of all the soul's passions, when they [the stoics] call them "opinions", "opinion" is used instead of "weak supposition", and "fresh"

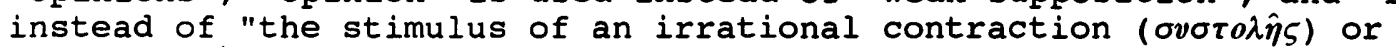

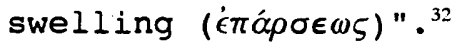

Diogenes Laertius tells us that even the three types of moderate impulse are also defined in physiological terms:

They [the stoics] say that there are three good feelings: joy, watchfulness, wishing. Joy, they say, is the opposite of pleasure, consisting in well-reasoned swelling ( $\tilde{\epsilon} \pi \alpha \sigma \iota v)$; and watchfulness is the

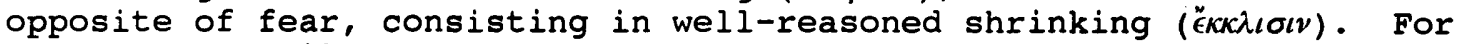
the wise man will not be afraid at all, but he will be watchful. They say that wishing is the opposite of appetite, consisting in wellreasoned stretching (desire, ö $\rho \xi(v) .{ }^{33}$

Thus it seems reasonable to conclude that the stoics considered all instances of impulse, whether moderate and reasonable or excessive and unreasonable, to be expansions or contractions: joy, watchfulness, and wishing are exhaustive of all moderate impulses; and appetite, pleasure, fear, and distress are exhaustive of all forms of passion.

We saw above that communication between body and commanding-faculty is described in terms of the soul- $\pi v \in \hat{v} \mu \alpha$ stretching out and relaxing, and also in terms of the mutual pressure upon each other of soul and body. Perception occurs when an object makes some sort of imprint on our sense organs which travels through the soul- $\pi v \in \hat{v} \mu \alpha$ to the commanding faculty in the heart. With this sort of relationship between soul and body, or more specifically,

\footnotetext{
${ }^{31}$ Andronicus, On Passions 1 (SVF 3.391, part; LS 65B).

${ }^{32}$ Stobaeus $2.88,22-89,3$ (SVF 3.378, part; LS 65C).

${ }^{33}$ Diogenes Laertius 7.116 (SVF 3.431; LS 65F(1-3)).
} 
commanding-faculty and body, it seems likely that bodily motion also was explained by the alteration of soul- $\pi v \in \hat{v} \mu \alpha$ in the heart being relayed through the soul- $\boldsymbol{v} \in \hat{v} \mu \alpha$ extending throughout the body. ${ }^{34}$ Thus Stoic impulse, like Aristotle's desire, has the function of translating what we want into what our bodies do.

This is my reconstruction of the stoic account of the physiological aspect of human action, and it is literally a reconstruction (the only one as far as I know) of the few relevant fragments we have. But I think it is right, and it reveals a physiological picture of perception and action nearly identical to Aristotle's. The differences are necessary to adapt Aristotle's theory to the Stoics' brand of materialism.

As similar as these two theories are, I think it would be perverse for Sandbach to insist that the Stoics developed their theory independently, and that the similarity is sheer coincidence. But there is one thing left to do before one can safely conclude that the Stoics adopted Aristotle's theory, and that is to show that there was not anyone else they could have gotten it from. We know that no other philosopher had a similar theory, and the only other likely source is the doctors, anatomists and physiologists of this period. To see the scientific context in which Aristotle and the Stoics were working, I will briefly survey the relevant theories current at that time. ${ }^{35}$ I would like to say that the Aristotelian and Stoic physiological theory I have described is perfectly unique--that would certainly strengthen my claim that the Stoics adopted Aristotle's theory. Unfortunately, things are not that simple.

IV

There were two anatomists before Aristotle's time that he knew of and referred to. First is Alcmaeon of Croton, whose floruit was probably about 450 B.C.E. Very little is known about Alcmaeon, but he was famous for first dissecting the eye ${ }^{36}$ and he was the first to mention passages (rópol) from the eyes, ears, nose, and maybe tongue, to the brain. He is said to have thought that all of the senses were connected in some way with the brain, ${ }^{37}$ but there is no evidence to suggest that he thought of the brain as the seat of consciousness or intellect. ${ }^{38}$ He is relevant to our present topic because he shows that Aristotle did not discover the passages from the sense organs in the head, but rather this would have been fairly common knowledge at the time. And Alcmaeon's attributing some special role to the brain anticipates what is soon to become a very controversial question.

Diogenes of Apollonia was a younger contemporary of Alcmaeon ( $\mathrm{fl}$. c . 440-430). Aristotle, in his History of Animals 3.2, describes and criticizes Diogenes' system of blood-vessels. Diogenes also spoke of passages connecting the ears and nose to the brain, but he seems to have thought that the eyes and

\footnotetext{
${ }^{34}$ Sambursky comments on this two-way movement of the $\pi v \in \hat{v} \mu \alpha$ within the body, Physics of the stoics, 22 .
}

${ }^{35}$ In chapter 1 of Hellenistic Philosophy of Mind, Julia Annas discusses medical theories from Aristotle through the Hellenistic period. While her treatment of this topic is, as she admits (p.20, n.11), cursory and selective, it is a good starting point for anyone interested in Hellenistic medicine as it influenced philosophy, and it contains the references and bibliography one would need to pursue more detailed research.

${ }^{36}$ Chalcidius, Commentary on the Timaeus, 279.

${ }^{37}$ Theophrastus, on the senses 26 (in stratton).

${ }^{38}$ On this see Beare, Greek Theories of Elementary Cognition, 251-52. 
tongue were connected to the heart. He does not address the question of there being one special place where thought or perception is centered, but heart and brain are both important to him.

He was rumored to be a follower of Anaximenes, ${ }^{39}$ and air played a significant role in his physiology. ${ }^{40}$ For instance, he thought that when we hear or smell something, the outside air enters our body and mixes with air in the brain to produce perception. He also associated air with thought, movement, and life in general. ${ }^{41}$ He seems to have thought that the veins contained air as well as blood, and it was this air that made thought and perception possible: Theophrastus reports that "the internal air is the real agent of perception, as it is a tiny fragment of divinity" (On the senses 42) and "thinking is due to pure dry air" (ibid. 44). However, Theophrastus adds that it is the mingling of air with our blood that causes thought and perception (ibid. 47). Diogenes is noteworthy because he attributed to air the sorts of functions which Aristotle soon afterwards attributed to $\pi v \epsilon \hat{v} \mu \alpha .{ }^{42}$ Plato should be mentioned, not because he was a physiologist of course, but because he dabbled in physiological issues in the Timaeus. What is relevant to our subject is Plato's locating the three parts of the soul in three parts of the body $(69 c-72 d)$. The rational soul is in the head, perhaps specifically in the brain, and the neck serves to block off the rational soul and protect it from being polluted by the lower parts. The spirited soul is in the chest area, perhaps in the heart; and the appetitive soul is in the region between midriff and navel, and is associated with the liver. ${ }^{43}$ plato speaks of "narrow channels" ( $\sigma \tau \epsilon \nu \omega \pi \alpha$, , 70b) through which the rational soul sends commands to the rest of the body, and these are quite possibly the veins. He also seems to consider the veins ( $\phi \lambda \dot{\epsilon} \beta \alpha \zeta$ ) to be carriers of perceptual information from the sense organs to the parts of the soul (64a68d), because he later describes two main veins extending from the left and right sides of the head to the opposite sides of the body whose functions are first, to fasten the head to the body, and second, to ensure that "sensations from both sides might be distributed over the whole body" (77e, Jowett translation). In his general account of perception Plato says the mobile particles within us (the fiery and airy ones, as opposed to the sluggish watery and earthy ones) receive an impression and then pass this motion on to

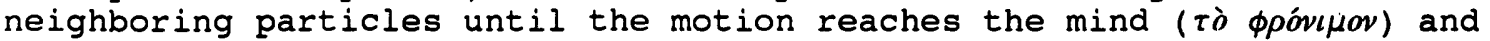
announces the perceived quality $(64 \mathrm{~b})$. It is not explicitly stated, but

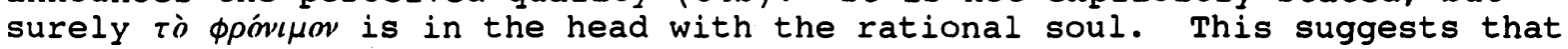
perceptual information travels from the sense organs to the brain.

However, when Plato goes on to discuss particular sense organs this account is complicated. Taste occurs when particles of food enter the small veins in the tongue and interact with the "moist delicate flesh" of these veins and/or the tongue $(65 c-d)$. Apparently sensation occurs in the tongue

${ }^{39}$ Diogenes Laertius 9.57.

${ }^{40}$ Theophrastus, on the senses $39-48$.

${ }^{41}$ Aristotle, De Anima 1.2, 405a21-25.

${ }^{42}$ Sambursky sees Diogenes' view of air as influencing the stoics' view of $\pi v \in \hat{v} \mu \alpha$, Physics of the stoics, 10 and 26-27. I believe this is right, and Diogenes is one of many (including Aristotle) that influenced stoic philosophy. Nevertheless, Diogenes does not have the specifically Aristotelian theory (of desires being expansions/contractions in the heart which cause bodily motion) which I find in Chrysippus.

${ }^{43}$ Galen takes himself to be defending Plato's view in locating the three parts of the soul in brain, heart, and liver in on the Doctrines of Hippocrates and Plato. 
itself, but Plato notes that these veins in the tongue extend all the way to the heart (65d). Smell occurs when particles enter the veins in the nose, and Plato says smells are distinguished only into the painful and the pleasant: the painful sort "irritate and disturb the whole cavity which is situated between the head and navel" and the pleasant particles have a soothing effect on the same region $(66 d-67 a)$. So in this case sensation is not limited to the sense organ, but seems to occur in the central portion of the body where the spirited and appetitive souls reside. Plato describes hearing thus: "sound is a blow which passes through the ears, and is transmitted by means of the air, the brain, and the blood, to the soul, and hearing is the vibration of this blow which begins in the head and ends in the region of the liver" (67b). This sounds as if the whole soul, from brain to liver, is involved in hearing. Vision is explained in terms of fiery particles entering the passages ( $\tau \dot{\alpha} \zeta$ $\delta \iota \epsilon \xi o ́ \delta o v \zeta, 67 e 8$ ) in the eye, and color perception seems to occur in the eye itself as the fiery particles "force their way through and melt" the passages and otherwise interact with the fiery and watery nature of the eyeball. The fifth sense of touch is not discussed. This is a convoluted theory of perception, and Plato seems unconcerned with making it any more consistent. What it reveals to us, however, is that Plato was at least familiar with contemporary physiological theory and was imposing his own tripartite conception of the soul on that theory.

The first really interesting and significant text for our purposes is the Hippocratic work "The Sacred Disease." Unfortunately this text is impossible to date accurately. Hippocrates himself was a contemporary of Socrates, but the Hippocratic corpus we have is believed to be composed of texts by various authors written at various times, all attributed to Hippocrates. But it is most likely that the bulk of the corpus was written between 430 and 330 B.C.E. (i.e. Aristotle's lifetime), so Aristotle could have been familiar with the theories of this text and the author of "The sacred Disease" may have known Aristotle's work. ${ }^{4}$ As we shall see, they seem to refer to each other in attacking the other's theory. The "sacred disease" is epilepsy, and the Hippocratic author refutes the claim that it is caused by the gods by explaining how it is really caused by a certain dysfunctional state of the brain. Along the way he states his view that the brain is the center of consciousness, and this text is the first explicit formulation of such a belief. But air still has a vital role to play, as it did in Diogenes of Apollonia. The author says that when we breathe air in through our nose and mouth the air first goes through our brain, then part of it goes to our stomach to cool it off, and the other part goes to our lungs and blood-vessels to be dispersed to the rest of the body. of this latter type of air he says "It induces intelligence and is necessary for the movement of the limbs" (\#10), but there is no explanation given of how this works.

He later says of the brain itself:

So long as it is healthy, it is the interpreter of what is derived from the air. Consciousness is caused by air. The eyes, ears, tongue, hands and feet perform actions. which are planned by the brain, for there is a measure of conscious thought throughout the body proportionate to the amount of air which it receives. The brain is also the organ of comprehension, for when a man draws in a breath it reaches the brain first, and thence is dispersed into the rest of the body, having left behind in the brain its vigor and whatever pertains to consciousness and intelligence. (\#19)

This is sounding more like Aristotle, with air apparently functioning something like his $n v \in \hat{v} \mu \alpha$ does, although as in Diogenes this is just the regular air we breathe in from the environment, whereas Aristotle's $\pi v \in \hat{v} \mu \alpha$ is

${ }^{44}$ On the dating issue see G.E.R. Lloyd's Hippocratic Writings, 9. 
a special innate substance which transmits movements from external perceived objects. The author of "The sacred Disease" gives us no details to explain how air and brain do what they do, but it sounds as if the air must somehow carry into the brain all perceptual information. It is very unclear how this could work since this air enters through our nose and mouth, not our sense organs, and the author does not try to make it work. of course he is interested in finding the cause of disease so as to cure it, so theories of perception, thought, and bodily movement are very peripheral to his goal. This Hippocratic author specifically attacks those who believe we think and feel with our heart, and one must wonder if he is referring to Aristotle. Likewise, when Aristotle, in Parts of Animals 2.10, is defending his view that the heart is the central organ of perception he specifically attacks those who say it is the brain. Since the date of "The sacred Disease" is unknown, we cannot say who knew who; but by the time that text was written, the battle lines between brain and heart were drawn. ${ }^{45}$

In the generation after Aristotle's death we know a little bit about two physiologists, Diocles of Carystus and Praxagoras of Cos. There is a striking difference between pre- and post-Aristotelian physiology, and that is the role of $\pi v \in \hat{v} \mu \alpha$. Once Aristotle introduced $\pi v \in \hat{v} \mu \alpha$ to explain perception and bodily motion, all subsequent physiology presupposed its existence. The argument then was only about what channels it flowed through, and disagreement over the central organ--brain or heart--also continued.

Diocles and Praxagoras agreed that $\pi v \in \hat{v} \mu \alpha$ issues forth from the heart and spreads to the rest of the body through the blood-vessels, ${ }^{46}$ but Praxagoras distinguished arteries from veins and said that $\pi v \in \hat{v} \mu \alpha$ runs through the arteries while the veins contain blood (fr. 9 and 85). One fragment says that

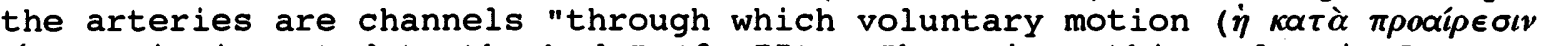
кívo(s) is imparted to the body" (fr.75). There is nothing else in Praxagoras to explain what this means or how motion is thus imparted, but since the arteries are full of $\pi v \epsilon \hat{v} \mu \alpha$ it obviously makes $\pi v \epsilon \hat{v} \mu \alpha$ responsible for transmitting bodily movement. This claim, coupled with Praxagoras' belief that the $\pi v \in \hat{v} \mu \alpha$ originates in the heart, which is the central organ, suggests that this fragment presupposes Aristotle's description of bodily motion in on the Motion of Animals. It is likely that Praxagoras accepts Aristotle's philosophical theory explaining movement, but modifies it in the light of his own distinction between arteries and veins. It is noteworthy that Praxagoras defends the heart as the center when the Hippocratic school claimed it was the brain.

Finally we have Herophilus and Erasistratus, two Alexandrian physicians famous for not only human dissection, but also human vivisection. ${ }^{47}$ They were active during the time of cleanthes and chrysippus, the second and third heads. of the stoa. They discovered the nerves, and distinguished the sensory nerves responsible for perception from the motor nerves responsible for movement. They proved by dissection that the nerves originated in the brain, and thus claimed the brain to be the central organ and source of thought and perception. This was thereafter the accepted scientific view, which makes it

${ }^{45}$ In fact there are two Hippocratic works which suggest that the heart is the center of thought: The short fragment on the Diseases of Maidens (Sigerist, A History of Medicine Vol.II, 287); and on the Heart \#10: "...man's intelligence, the principle which rules over the rest of the soul, is situated in the left chamber [of the heart]" (Hippocratic Writings, ed. Lloyd, 351).

${ }^{46}$ Diocles fr. 59, Praxagoras fr. 70 and 74 (in Stekerl).

${ }^{47}$ Supposedly, Herophilus was a student of Praxagoras and Erasistratus was a student of Chrysippus of Cnidus (Sigerist, Vol. II, 266). I see no significance in Erasistratus' teacher having the name of our stoic, but it is peculiar enough to note. 
significant that Chrysippus rejected the best scientific evidence of his time and instead embraced the outdated Aristotelian and Praxagorean view that the heart is the central organ. ${ }^{48}$

Erasistratus, like Praxagoras, believed the arteries were full of $\pi v \in \hat{v} \mu \alpha$ while the veins contained blood, but added that the nerves too were filled with $\pi v \in \hat{v} \mu \alpha$. In fact, he described the nerves as "that through which voluntary motions are brought about," 49 almost exactly the same words Praxagoras had used of the $\pi v \in \hat{v} \mu \alpha-f i l l e d$ arteries. Thus $\pi v \in \hat{v} \mu \alpha$ retained its Aristotelian functions of enabling the body to move and perceive. But again, as with Diogenes, this $\pi v \in \hat{v} \mu \alpha$ originates as air breathed in from the environment, and is mysteriously changed from air to $\pi v \in \hat{v} \mu \alpha$ within the body. Aristotle on the contrary believed the $\pi v \in \hat{v} \mu \alpha$ to be innate, a special type of substance analogous to the ether composing the stars, and which transmits the form of the human soul from parent to offspring.

Now with this brief survey of ancient physiology in mind we must ask, could any of this be the source of Chrysippus' theory of how our wants are translated into bodily movement? I think the answer is no.

There is an obvious continuity among the theories I have just described. First, all are concerned to various degrees with how perceptual information travels through the body. But this was an ancient question, and Empedocles was perhaps the first to venture an answer with his doctrine of effluences and channels or pores through which these particles travel. He even said that we think with the blood around our heart, which may suggest that the heart was the central organ for him, although I doubt Empedocles thought in such terms. Aristotle and the Hippocratic author were the first to explicitly centralize thought and perception in one organ, and it is only after Aristotle that we see physiologists and philosophers taking sides. Praxagoras and Chrysippus agreed with Aristotle that the heart was central, while Herophilus and Erasistratus proved the Hippocratic author right.

Second, many of these doctors and physiologists were interested in the mechanics of how the body moves. The two above-mentioned fragments of Praxagoras and Erasistratus associating $\pi v \in \hat{v} \mu \alpha$ with voluntary motion are tantalizing evidence of what may have been fully developed theories of movement. There is undoubtedly a fascinating story to tell about the corresponding development of philosophical and physiological theories of perception and voluntary movement. ${ }^{50}$

Nevertheless, however we explain the relationship between philosophers and physiologists, the fact remains that there is in the medical fragments nothing like Aristotle's theory of desires causing the expansion and contraction of $\pi v \in \hat{v} \mu \alpha$ in the heart which in turn moves the body, and this is what we find in Stoic fragments which is peculiarly Aristotelian.

All things considered then, it is most likely that chrysippus did adopt at least Aristotle's description of the physiology of action. In the larger argument $I$ am in the process of composing, this claim is one step towards showing how Stoic determinism grew from Aristotelian roots.

${ }^{48}$ of course, he had philosophical reasons for keeping the mind in the heart. On this see Annas' Hellenistic Philosophy of Mind, 25 and 68-70.

${ }^{49}$ Galen, on Melancholy 5.

${ }^{50}$ See, for instance, Solmsen's "Greek Philosophy and the Discovery of the Nerves." 


\section{BIBLIOGRAPHY}

Annas, Julia E. Hellenistic Philosophy of Mind. Berkeley: University of California Press, 1992.

Arnim, H. von. Stoicorum Veterum Fragmenta, 3 vols. Leipzig, 1903-5. Vol. 4, indexes by $M$. Adler. Leipzig, 1924.

Barnes, Jonathan. The Complete Works of Aristotle, 2 vols. Princeton: Princeton University Press, 1984.

Beare, John I. Greek Theories of Elementary Cognition: From Alcmaeon to Aristotle. Oxford: Clarendon Press, 1906.

Guthrie, W.K.C. A History of Greek Philosophy, vol. 6. Cambridge: Cambridge University Press, 1983.

Hahm, David E. "Aristotle and the Stoics: A Methodological Crux." Archiv fur Geschichte der Philosophie 73 (1991): 297-311.

- The origins of Stoic Cosmology. Columbus: Ohio State University Press, 1977 .

Hamilton, Edith and Huntington Cairns, edd. The Collected Dialogues of Plato. Princeton: Princeton University Press, 1987.

Inwood, Brad. Ethics and Human Action in Early stoicism. Oxford: Clarendon Press, 1985.

Lacy, Phillip de. Galen: On the Doctrines of Hippocrates and Plato. Corpus Medicorum Graecorum, V. 4, Pt. 1 \& 2. Berlin: Akademie-Verlag, 1980.

Lear, Jonathan. Aristotle: The Desire to Understand. Cambridge: Cambridge University Press, 1988.

Lloyd, G.E.R. Hippocratic Writings. London: Penguin Books, 1983.

Long, A.A., and D.N. Sedley. The Hellenistic Philosophers, 2 vols. Cambridge: Cambridge University Press, 1987.

Nussbaum, Martha C. Aristotle's De Motu Animalium: Text with Translation, Commentary and Interpretive Essays. Princeton: Princeton University Press, 1978.

Peck, Arthur I. "The Connate Pneuma: An Essential Factor in Aristotle's Solutions to the Problems of Reproduction and Sensation." Science, Medicine, and History, vol. 1. E. Ashworth Underwood, ed. London: Oxford University Press, 1953.

-----. Aristotle: Generation of Animals. Loeb edition. Cambridge: Harvard University Press, 1942.

Ross, G.R.T. Aristotle: De Sensu and De Memoria. New York: Arno Press, 1973.

Sambursky, S. The Physics of the Stoics. London: Routledge \& Kegan Paul, 1959.

Sandbach, F.H. Aristotle and the Stoics. [Cambridge Philological society Supp. Vol. 10.] Cambridge: Cambridge Philological Society, 1985.

The Stoics. London: W.W. Norton, 1975. 
Sigerist, Henry E. A History of Medicine, 2 vol. New York: Oxford University Press, 1951-61.

Solmsen, Friedrich. "Greek Philosophy and the Discovery of the Nerves." Museum Helveticum 18 (1961): 150-97.

Staden, Heinrich von. Herophilus: The Art of Medicine in Early Alexandria. Cambridge: Cambridge University Press, 1989.

Stekerl, Fritz. The Fragments of Praxagoras of Cos and His School. Philosophia Antiqua 8. Leiden: E.J. Brill, 1958.

Stratton, George Malcolm. Theophrastus and the Greek Physiological Psychology Before Aristotle. London: George Allen \& Unwin Ltd., 1917. 